\title{
Deformation Assisted Homogenization of IN-706 Ingot and Effect on Microstructure and Mechanical Properties
}

\author{
A.K. Chakrabarti, E.A. Beaumont, M.C. Brest, D.F. Carbaugh, W.F. \\ Kuhlman and E.D. Seaton, Alcoa Technical Center and Alcoa Forging \\ Division.
}

\begin{abstract}
Triple-melted VIM-ESR-VAR large IN-706 ingots (32-36 in. dia x 66-100 in. height) are cast to fabricate very large forgings utilized for several end applications. Although macrosegregations, greater than $1 / 16$ in. dia, are not detected in most of these ingots, some microsegregations rich in hardening elements $(\mathrm{Nb}, \mathrm{Ti})$ are observed in ingot sections. A thermal treatment of $1600^{\circ} \mathrm{F} / 1-2 \mathrm{hr}$ followed by air cooling reveals these segregated areas which exhibit a high density of needle-type precipitates [possibly delta $(\delta)$ or eta $(\eta)$ phase]. Conventional homogenization of these ingots in the range of $2000^{\circ}$ to $2200^{\circ} \mathrm{F}$ for 18 to $72 \mathrm{hr}$ did not eliminate this type of microsegregation. Attempts were made to study the effect of mechanical deformation (hot working) and homogenization on microsegregation.

Optical micrographs indicate that a $2: 1$ upset with a redraw followed by a $2000^{\circ}$ to $2200^{\circ} \mathrm{F} \pm 25^{\circ} \mathrm{F}$ homogenization for 24 to $48 \mathrm{hr}$ reduces the extent of microsegregation. However, electron microprobe line scan and spot scan analysis did not reveal a significant difference for $\mathrm{Nb}$, Ti distribution between the conventionally homogenized and deformation assisted homogenized billet stock. Small scale pancake forgings ( 6 in. dia $\mathrm{x} 1$ in. thick) fabricated from these billet stocks, however, indicate that the deformation assisted homogenized ingot sections develop a more uniform grain size and microstructure compared to those from a conventionally homogenized ingot section.
\end{abstract}

\footnotetext{
Superalloys 718, 625,706 and Various Derivatives Edited by E.A. Loria

The Minerals, Metals \& Materials Society, 1994
} 